\section{Psicologia Escolar \\ e Educacional}

ARTIGO

DOI: http://dx.doi.org/10.1590/2175-35392021223573

Localizador - e223573

\title{
A VIOLÊNCIA NA EDUCAÇÃO: CONSIDERAÇÕES DE PROFESSORES VIOLENTADOS
}

\author{
Mírian Alves Carvalho ${ }^{1{ }^{\mathbb{D}}}$;Sonia Mari Shima Barroco ${ }^{1 \mathbb{D}}$
}

\begin{abstract}
RESUMO
A pesquisa teve como objetivos compreender a violência relacionada à educação, subsidiada pela Psicologia HistóricoCultural (PHC) e conhecer o que expressam professores de escolas estaduais de um município do Paraná sobre a violência na educação. Contou com investigações bibliográfica e de campo. Recuperaram-se estudos teóricos sobre violência na atual sociedade capitalista e seus impactos sobre a constituição social do psiquismo humano. A investigação de campo foi elaborada por meio de entrevistas semiestruturadas com catorze professores que sofreram forte violência policial em protesto contra o desmonte da educação pública, abordando-se suas percepções sobre a violência manifesta na escola. Os resultados das investigações apontam para os fatores multicausais e estruturais da violência na educação, não sendo adequada a designação de violência escolar. Os professores, mesmo impactados com a violência sofrida, não desistiram de suas atuações profissionais em prol da formação humana.
\end{abstract}

Palavras-chave: violência; educação; psicologia histórico-cultural.

\section{Violence in education: considerations of violated teachers}

\begin{abstract}
The research aimed to understand the violence related to education, subsidized by Historical-Cultural Psychology (HCP), and to know what teachers from state schools in a municipality in Paraná express about violence in education. It had bibliographic and field investigations. Theoretical studies on violence in the current capitalist society and their impacts on the social constitution of the human psyche were recovered. The field investigation was carried out through semi-structured interviews with fourteen teachers who suffered strong police violence in protest against the dismantling of public education, addressing their perceptions of the violence manifested at school. The results of the investigations point to the multicausal and structural factors of violence in education, and the designation of school violence is not appropriate. Teachers, despite being impacted by the violence they suffered, did not give up their professional activities in favor of human training.
\end{abstract}

Keywords: violence; education; historical-cultural psychology.

\section{La violencia en la educación: consideraciones de profesores violentados}

\section{RESUMEN}

En la investigación se tuvo como objetivos comprender la violencia relacionada a la educación, subsidiada Psicología Histórico-Cultural (PHC), y conocer lo que expresan profesores de escuelas estaduales de un municipio de Paraná sobre la violencia en la educación. Contó con investigaciones bibliográfica y de campo. Se recuperaron estudios teóricos sobre violencia en la actual sociedad capitalista y sus impactos sobre la constitución social del psiquismo humano. La investigación de campo fue elaborada por intermedio de entrevistas semiestructuradas con catorce profesores que sufrieron fuerte violencia policial en protesta contra el desmontaje de la educación pública, abordándose sus percepciones sobre la violencia manifiesta en la escuela. Los resultados de las investigaciones apuntan para los factores multicausales y estructurales de la violencia en la educación, no siendo adecuada la designación de violencia escolar. Los profesores, aún impactados con la violencia sufrida, no desistieron de sus actuaciones profesionales en pro de la formación humana.

Palabras clave: violencia; educación; psicología histórico-cultural.

\footnotetext{
1 Universidade Estadual de Maringá - Maringá - PR - Brasil; mirianpsicologa@nrecascavel.com; contato@soniashima.com.br
} 


\section{INTRODUÇÃO}

O presente artigo aborda pesquisa circunscrita à violência que se relaciona à educação e teve como objetivos: compreender a violência relacionada à educação, apoiada na Psicologia Histórico-Cultural e conhecer o que expressam os professores de escolas públicas da rede estadual de um município do Oeste do Paraná sobre a violência na educação. A busca desses objetivos visou contribuições possíveis da Psicologia Escolar para o enfrentamento desse fenômeno.

Como notamos a necessidade de que a Psicologia - enquanto ciência que estuda o psiquismo humano e busca explicá-lo-se manifestasse a respeito desse tema, a pesquisa oportunizou a expressão de professores, num processo de escuta em um momento de muita comoção, após a violência policial ocorrida no dia 29/04/2015, em Curitiba-PR. Consideramos que a Psicologia não pode se furtar à análise das relações permeadas e/ou travadas em meio à violência. Para o enfrentamento de algo tão sério como o ocorrido, a sociedade precisa ter mais elementos que permitam conhecer o que ocorreu com os professores e funcionários da educação naquela situação. Também ponderamos que a Psicologia Histórico-Cultural (PHC) apresenta um escopo teórico para apreendermos os impactos da violência na educação e na constituição dos profissionais que atuam nas escolas.

Certas da amplitude do nosso tema de pesquisa "violência na educação", visto que ele apresenta vários desdobramentos, delimitamos a violência na educação pública sob a organização capitalista e o modelo de sociedade atual. Apresentamos diferentes estudos a esse respeito que abordam causas, conceitos, manifestações e ações de enfrentamento às suas diferentes formas, como, por exemplo, Martin-Baró (1997, 2015), Chauí (1999), Castro, Abramovay, Rua e Andrade (2001), Silva (2006), Vázquez (1977) e Barroco e Costa (2014). Esses estudos selecionados foram realizados antes de 2015, ano em que os professores da rede estadual de educação do Paraná sofreram grande violência ao se posicionarem contra o governo estadual, pois, entre outros aspectos, este estava sequestrando valores que comprometiam a saúde financeira da Paraná previdência e a aposentadoria dos trabalhadores da educação. O ocorrido foi amplamente noticiado pela imprensa brasileira e internacional e gerou uma pesquisa específica denominada "A violência na educação: o que expressam professores das escolas públicas da rede estadual no município de Cascavel/PR que passaram por situações de violência" (Carvalho, 2017).

Em meio a situações como a apontada, salientamos a importância de recuperar os estudos da $\mathrm{PHC}$ em relação ao papel fundamental da escola para o desenvolvimento humano, com base em autores clássicos como Vygotski ${ }^{1}$ (2000); Vigotski (1996), Leontiev $(1978 ; 1988)$ e Luria (1979), que têm como pressuposto que o psiquismo humano se constitui histórica e socialmente. Assim, investigar o fenômeno da violência relacionada à educação, impôs o exercício de irmos para além da aparência - que não revela as suas múltiplas determinações de modo imediato. Nesse contexto, a violência na educação não pode ser tomada apenas por episódios distintos, mas como um todo articulado, como realidade violenta.

Pelo já publicado por diferentes autores, nenhum dos aspectos que se referem à violência foi considerado finalizado em suas investigações - até porque se trata de um fenômeno que vem se agudizando. Isso é notório em levantamentos como a Pesquisa Nacional de Saúde do Escolar (PeNSE), realizada em 2009, 2012 e 2015 pelo Instituto Brasileiro de Geografia e Estatística (IBGE) e Ministério da Saúde e da qual participaram alunos do 9o ano do Ensino Fundamental e estudantes de 13 a 17 anos.

No Relatório Mundial Sobre Violência e Saúde 2014, a Organização Mundial de Saúde (OMS) apresenta um conceito que já vinha sendo trabalhado por ela desde 1996 e que já era tema de diferentes resoluções desta organização desde 1986, "Violência é o uso intencional de força física ou poder, real ou mediante ameaça, contra um indivíduo, ou contra um grupo ou uma comunidade, que resulte ou tenha grande probabilidade de resultar em ferimentos, morte, danos psicológicos, prejuízo ao desenvolvimento ou privação" (2014, p. 84).

A PeNSE 2012 já assumia esse conceito considerando a violência como um problema para os setores de justiça criminal e de defesa. Na PeNSE 2015, assim como nas edições anteriores, pesquisaram-se formas de violência sofridas pelos estudantes no âmbito familiar e escolar, como bullying e brigas, agressão física em locais públicos com uso de arma branca ou de fogo, lesões e ferimentos sofridos, sentimento de insegurança no trajeto casaescola, escola-casa, violência no trânsito.

A violência trata-se, portanto, de um fenômeno dinâmico, em crescimento e que, a cada dia ou situação, revela facetas diferenciadas em sua expressão,

\footnotetext{
${ }^{1}$ Neste artigo, optamos por empregar a grafia Vigotski, por ser a mais utilizada nas recentes traduções das obras do autor. As diferentes grafias utilizadas nas publicações serão preservadas quando citadas no presente texto.
} 
bemcomo nos fatos precipitadores ${ }^{2}$. Considerando o caráter histórico e relacional do fenômeno da violência, Chauí $(1999$, p. 3) traz um conceito sobre o tema:

[...] violência vem do latim vis, força, e significa [...] tudo o que age usando a força para ir contra a natureza de algum ser (é desnaturar); todo ato de força contra a espontaneidade, a vontade e a liberdade de alguém (é coagir, constranger, torturar, brutalizar); todo ato de violação da natureza de alguém ou de alguma coisa valorizada positivamente por uma sociedade (é violar); todo ato de transgressão contra o que alguém ou uma sociedade define como justo e como um direito.

Essa conceituação amplia a compreensão do sentido da violência e da sua real magnitude. (Chauí, 1999) teoriza que, sendo nossa sociedade estruturalmente violenta, não ficam ocultas as desigualdades sociais, econômicas e culturais, a corrupção, a intolerância política, religiosa e sexual, o autoritarismo nas relações sociais e o sexismo, aspectos considerados formas de violência. Para a autora, ter clareza da noção de violência permite a atuação coletiva no seu enfrentamento.

Martin-Baró $(1997,2015)$ ganhou destaque ao analisar a violência em sua origem estrutural e suas múltiplas formas, seus níveis de significação e seus efeitos históricos. Pontua que um ato considerado violento em um momento histórico determinado retrata os conflitos e as determinações sociais e econômicas daquela sociedade. Apresenta diversas análises que serviram não somente para enfrentamento aos vários golpes de Estado ocorridos em El Salvador entre 1932 a 1972, mas para compreendermos os dias atuais no Brasil e no mundo. Aborda que a violência se apresenta sob diferentes aspectos e com o emprego de diferentes estratégias. É original quando discorre sobre a "institucionalização da calúnia" (Martin Baró, 2015), como uma ação orquestrada por dirigentes, que consente com a condenação e a responsabilização das vítimas, desmerecendo-as por meio de calúnias, que produzem justificativas para o emprego da violência, em prol de dada dominação pretendida.

Silva (2006) revisa alguns estudos sobre a violência relacionada à educação, concebendo-a como fenômeno social e historicamente determinado. Tratando da

\footnotetext{
${ }^{2} \mathrm{O}$ assassinato de George Perry Floyd Jr. em 25 de maio de 2020 - Minneapolis/EUA, por exemplo, deixou mais evidente a violência sofrida pelos negros no mundo todo, não somente no trato com a polícia, mas em todas as instituições, como na escola. A reação provocada mundialmente deu notoriedade ao movimento Black lives matter - Vidas negras importam (https://blacklivesmatter.com/). Inúmeros depoimentos de pessoas que sofrem violências pelo racismo têm sido divulgados.
}

formação de professores para enfrentarem a violência na escola, pontua ser necessário que compreendam a forma como a sociedade está organizada, para melhor embasar as discussões relacionadas e buscar formas de lidar com as pessoas envolvidas.

A compreensão sobre a violência na educação ou na escola tem sofrido mudanças ao longo da história, o que demanda revisão em sua conceituação, segundo Costa (2014). Isso não é simples, pois sendo um fenômeno histórico, na sua totalidade, é social e mutável e está em constante transformação; assume diferentes facetas. Alguns dos estudos mais abrangentes sobre a violência e com enfoques multidimensionais têm adotado uma conceituação mais ampla, incorporando dimensões socioculturais e simbólicas, como constam em pesquisas brasileiras publicadas (Barreira, 1999; Minayo, 1999; Castro et al., 2001; Abramovay, 2002).

Para respaldo na conceituação desse fenômeno, resgatamos o que expõe Vázquez (1977, p. 382) em "Filosofia da Práxis", onde discorre sobre a naturalização da violência "como modo de vida": é a violência da miséria, da fome, da prostituição ou das enfermidades, que já não é a resposta à outra violência potencial ou em ato, mas sim a própria violência como modo de vida porque assim o exige a própria essência do regime social.

Para Vázquez (1977) a violência, muitas vezes considerada natural e necessária, constitui a essência da ordem burguesa; materializada tanto na ordem econômica, quanto na sua sustentação ideológica, sendo a miséria e a pobreza condições de vida de uma grande parte das pessoas. Além disso, cria condições para que se mantenha a riqueza para usufruto de uma pequena parcela da população. Também a violência envolve aspectos econômicos, políticos e ideológicos, tendo relação com o acesso ou não aos direitos sociais e guarda estreita relação com a mercantilização das relações humanas.

Na direção apontada por esses autores, elegemos a PHC como uma matriz subsidiadora para a pesquisa, pois consideramos que apresenta elementos explicativos da sociedade e do ser humano numa perspectiva históricodialética. Pela PHC reconhecemos a constituição social do psiquismo daqueles que violentam, são violentados, são impactados pela violência, ou mesmo daqueles que parecem não se incomodar com ela. Em outras palavras, as condições objetivas de existência, o nível de conhecimento do mundo, o modo como ele se desvenda ou é desvendado, como dele se retiram suas leis de funcionamento e dele se extrai matéria para compor a riqueza da sociedade, encaminham para a formação do que é propriamente humano no psiquismo: as funções psicológicas superiores (FPS), a personalidade, a consciência. 
Sob essa perspectiva, podemos dizer que a precariedade das condições de vida da população resulta do modo de produção e das relações sociais dela derivadas. Assim, se tomarmos como base a sociedade capitalista, veremos que nela os homens, para manterem/reproduzirem a vida, produzem a riqueza e a miséria, impõem e quebram regras e valores, determinam um dado modus vivendi. Isso se dá cotidianamente, de tal modo que os processos que garantem o modo de vida instituído passam a ser considerados como naturais, necessários, inexoráveis. Contudo, a História revela que as diferentes épocas (Antiguidade, Idade Média, Idade Moderna e Idade Contemporânea) contam com modos de produção específicos; com relações sociais que lhes são próprias e das quais derivam determinadas concepções de vida, de sociedade, de ser humano.

Nos dias atuais, sob a reprodução incontrolável do capital, notamos um aparato ideológico condizente, em que é negado o acesso às conquistas humanas decorrentes de tal acumulação nas diversas áreas da vida e do conhecimento. Esse contexto, que se acentuou nas últimas quatro décadas, é continente ao acirramento da violência em todos os espaços sociais, como é o caso da escola pública, seja por ela estar sendo deixada em agonia devido às políticas sob a ótica neoliberal, seja pelo processo de exclusão socioeconômica que tem se intensificado, levando ao recrudescimento de práticas de violência.

De tão frequentes, a violência social e na escola são entendidas como naturais ou inevitáveis, decorrentes de pessoas (geneticamente comprometidas, emocionalmente abaladas e/ou educacionalmente malformadas) ou de grupos, entidades, instituições ou órgãos que funcionam descolados da totalidade, da lógica capitalista. Esse entendimento biologicista e naturalizante não reconhece que a violência é a expressão da luta de interesses antagônicos; que a violência tem intrínseca relação com a luta de classes sociais antagônicas.

Barroco e Costa (2014), em seus estudos sobre violência na escola subsidiados pela PHC, pontuam que a violência não é somente da escola, mas nela se manifesta, como ocorre em quaisquer outros espaços e instituições onde os sujeitos estejam. Nessa perspectiva, considera-se fundamental desconstruir a concepção arraigada na sociedade de que os indivíduos nascem com personalidade violenta, isto é, herdam-na dos pais ou ascendentes. É, pois, necessário contar com subsídios para uma reflexão e análise crítica dos pressupostos psicológicos e pedagógicos presentes no espaço escolar, dentro da temática da violência. Com isso, torna-se possível pensar alternativas educativas/formativas para o enfrentamento das situações de violência que se manifestam na escola, indo para além da prática repressora e reativa que essa concepção criticada suscita.

Barroco e Costa (2014) defendem uma concepção de homem que se faz segundo as leis da História e cuja formação como humano está em consonância com as condições histórico-sociais de dado espaço temporal, geográfico e socioeconômico. As autoras postulam, ainda, que o homem não nasce humanizado, ele precisa conquistar esta condição na batalha que trava diariamente em busca da sobrevivência. Dito de outro modo, um comportamento violento não é naturalmente violento, pois nem o homem é naturalmente humano.

Pela perspectiva teórica assumida nesta pesquisa, a escola é reconhecida como fundamental para a formação e humanização dos sujeitos, podendo ser considerada, após a família ou o grupo primário, como a segunda instituição mais importante para o processo formativo humano. Por meio dela podem se apropriar, de modo gradativo e sistematizado, daquilo que a humanidade tem produzido, sendo que o conteúdo curricular impacta no modo como compreendem o mundo e a si mesmos. A escola lhes permite contar com recursos instrumentais que alteram seus psiquismos (a percepção, o pensamento, a memória, a linguagem etc.), promovendo-lhes o desenvolvimento das FPS - que se caracterizam pela intencionalidade e consciência com que são empregadas, e por serem geneticamente de ordem cultural (Vygotski, 2000).

Desse modo, é preocupante que a escola seja transformada num espaço de reprodução recorrente de situações de violência, de tal modo que o processo ensino-aprendizagem seja impedido de se concretizar de modo mais efetivo e em prol do domínio dos saberes curriculares por parte dos alunos.

Num momento em que a sociedade tem se pautado numa lógica que conta com a violência (sob diferentes meios e formas) para domínio e subjugação de pessoas, grupos, povos e nações, é preciso que se estabeleçam diferentes mediações para que a escola não seja um campo aberto e fecundo para a sua franca reprodução. Para um posicionamento educativo é necessário compreender as relações que determinam essa lógica, não apenas negá-la ou encobri-la. Na organização social atual, mais que em outros momentos históricos, a violência aparece expandida sob a forma de exploração do homem pelo homem, o que nos permite apontar para a consideração da violência estrutural na constituição das relações interpessoais (Ros, 2014). Nesse contexto, as relações têm se corrompido porque a barbárie avança a passos largos na sociedade contemporânea e atinge todos os campos da prática social, dentre eles a família e a escola.

Nessa direção, para o que a violência produz na escola e em nós, sujeitos, Silva (2006) aponta para o individualismo difundido pelo neoliberalismo, a competição acirrada e a exploração do capital. Isso 
tem produzido a degeneração das relações sociais, aumentando a falta de respeito nessas relações e contribuindo para um clima desfavorável ao ensino e aprendizagem de conteúdos curriculares (científicos) no interior da escola. Mas isso se dá em anuência a uma dada concepção de educação pública, que prevê quanto se deva empenhar para que os seus usuários possam, de fato, ter uma formação integral, universal.

\section{MÉTODO}

Reconhecendo que os seres humanos se constituem como tais a partir das relações sociais que estabelecem, para respondermos às questões da violência que envolve a educação escolar é preciso que a análise dos fenômenos se dê num exercício histórico-dialético, não se prendendo à aparência. Vygotski (2000) entende ser necessário à Psicologia que identifique a gênese dos fenômenos ou objetos, que busque investigar a historicidade deles, a relação que estabelecem com a prática social em dado espaço temporal, geográfico, enfim, a sua relação com a cultura. O autor parte do entendimento de que eles se apresentam e são percebidos de acordo com dadas condições sóciohistóricas.

Esse entendimento esteve presente na pesquisa ora relatada, composta por investigações bibliográfica e de campo, e vinculada a uma pesquisa interinstitucional mais ampla intitulada "Alternativas para Enfrentamento da Violência na Educação Básica: uma demanda à Psicologia Escolar" (UEM, Fundação Araucária /Paraná, 2012-2017).

Com o objetivo de conhecer o que os professores expressam em relação à violência na educação, para a coleta de dados foi utilizada como instrumento a entrevista semiestruturada. Quanto à pesquisa de campo, segundo Fonseca (2011), consiste na observação de fatos e fenômenos como ocorrem espontaneamente, quando se realiza coleta de dados junto a pessoas com diferentes recursos. Em relação à entrevista semiestruturada, Gil (1996) afirma que ela é, seguramente, a mais flexível de todas as técnicas de coleta de dados de que dispõem as ciências sociais e considera sua relevância para as ciências humanas.

O projeto da referida pesquisa foi submetido ao Comitê Permanente de Ética em Pesquisas Envolvendo Seres Humanos (COPEP/UEM), tendo sido aprovado, conforme parecer do comitê, de acordo com as recomendações éticas. Após a autorização da pesquisa, os entrevistados foram orientados sobre os objetivos, a participação voluntária e a liberdade para desistirem sem sofrerem quaisquer ônus, o sigilo, a confiabilidade e a confidencialidade das respostas e de suas identidades. Quanto à identidade dos entrevistados, sugerimos que escolhessem um pseudônimo, como o nome de um autor, escritor, educador ou artista que lhes fossem significativos. As dúvidas dos participantes foram respondidas, bem como realizadas a leitura e assinatura do Termo de Consentimento Livre e Esclarecido (TCLE). As entrevistas foram gravadas e, posteriormente, os áudios foram transcritos e submetidos a recorrentes leituras e análises.

A seleção dos professores participantes obedeceu aos critérios: que tivessem sofrido ou vivenciado pessoalmente situações de violência na cidade de Curitiba/PR, em 29 de abril de 2015 e com disponibilidade para as entrevistas, com o consentimento do Núcleo Regional de Educação do município. Foram identificados 26 professores que atendiam aos critérios expostos, mas 14 (catorze) professores se disponibilizaram a participar.

A entrevista semiestruturada, com cerca de 60 minutos de duração, gravada e transcrita, enfocou os eixos: Formação e Atuação Profissional, Percepções da Educação/Escola Atual, da Violência no Mundo e na Escola, Violência no 1을 Semestre/2015 e Perspectivas para a Educação e Vida Pessoal.

\section{RESULTADOS E DISCUSSÃO}

Sobre o eixo: "Formação e atuação profissional", dos catorze entrevistados, onze eram professoras e três eram professores, sendo que cinco profissionais $(35,71 \%)$ estão na faixa de idade de 25 a 35 anos; cinco $(35,71 \%)$ contam com 36 a 46 anos de idade; e quatro professores (28,57\%) com 47 a 58 anos de idade. Quanto ao tempo de magistério, prevaleceu o tempo de cinco a quinze anos de profissão, apontado por nove professores $(64,29 \%)$. Sobre a natureza do vínculo, somente um professor não é do quadro próprio do magistério, atuando por meio do Processo Seletivo Simplificado (PSS). Em relação à carga horária de trabalho, 11 professores (78,57\%) cumprem 40 horasaula semanais, e três $(21,43 \%)$ cumprem 20 horas-aula semanais.

Quanto à formação acadêmica, todos os professores têm graduação nas áreas de atuação; 10 (71,43\%) têm Especialização; três (21,43\%) têm Mestrado; um professor $(7,14 \%)$ tem Doutorado. Em relação à área de atuação, cinco professores $(35,71 \%)$ atuam na área de Linguagem: Língua Portuguesa, Língua Estrangeira Moderna, Artes e Educação Física; quatro (28,57\%) na área das Ciências Humanas (História/Geografia e Filosofia/Sociologia); dois (14,29\%) nas Ciências Exatas (Matemática), e três $(21,43 \%)$, com formação em Pedagogia atuam na Equipe Pedagógica e na Sala de Recursos Multifuncionais (SRMF).

No eixo: "Violência no 1을 Semestre de 2015", ao serem indagados sobre "o que teria levado às manifestações no início do ano letivo de 2015", todos responderam ser a luta para manutenção dos direitos conquistados, como expôs Milton Hatoum: "Essa tentativa de retirada massiva de direitos, eu acredito 
que foi o que motivou 2015".

A esse respeito Galvão (2015) expõe a organização de novas formas, novos tipos e espaços de luta para atender às demandas dos trabalhadores, como no dia 29/04/2015, mediante o processo de exploração e opressão capitalista, "é preciso mais do que olhar para as particularidades dos movimentos sociais e populares [...], mas enxergá-las tendo por base a totalidade que as envolve a partir da contradição capital/trabalho" (p. 12).

A prevalência das respostas demanda cuidado para não perdermos a perspectiva da totalidade, pois a luta do professor e de toda a classe trabalhadora não pode ser somente para "manter os direitos conquistados", mas abranger as origens dos sofrimentos vivenciados, que é a reafirmação e a ampliação do Estado neoliberal. Nesse sentido, Martins (2006) contribui ao expor sobre uma melhor compreensão dos fatos: "a análise dialética da relação entre o singular e o universal [...] torna possível a construção do conhecimento concreto, [...] a ênfase conferida ao particular não se converte no abandono da construção de um saber na perspectiva da totalidade" (p. 12). É preciso reconhecer que o capital faz uso de diferentes estratégias - como a produção da calúnia, teorizada por Martin Baró (2015) - para conter toda forma de resistência da classe trabalhadora, intensificando a repressão e criminalização dos movimentos reivindicatórios.

Solicitamos que os professores relatassem como foi estar em Curitiba no dia 29 de abril de 2015. Ao relembrarem e relatarem ficaram mobilizados; manifestaram reações emocionais com choros (alguns de modo discreto, com os olhos marejados, outros com lágrimas correndo pelas faces) e vozes embargadas, demonstrando sentimentos como tristeza e revolta. Apontaremos alguns pontos significativos que emergiram nos relatos.

[...] Eles corriam atrás da gente, sem parar, com bombas. Pessoas que caíam, se machucavam. Você correndo, aquele helicóptero em cima, os policiais correndo atrás de nós, como se fosse uma bandida. [...] as bombas vinham dos prédios de trás, aí isso foi desesperador, estávamos num cerco. [...] teve senhoras caindo lá dentro e as pessoas riam, como se aquilo fosse engraçado. Então isso foi uma violência, uma coisa que foi traumática, foi horrivel. Ai conseguimos correr. As pessoas se perderam. A gente tentava ajudar. [...] (Marlene Sapeli - - Pedagoga e pesquisadora brasileira)

Nesse cenário de guerra, os professores revisam o que as leis, as políticas e os tratados internacionais preconizam, ao mesmo tempo em que tentam se proteger e acudir uns aos outros. Ele revela o ataque literal aos trabalhadores que se opuseram ao não cumprimento do previsto em relação ao reajuste salarial, entre outros pontos que conferem a desvalorização e o desmonte da educação pública, sendo essa uma das formas de expressão de manutenção da hegemonia do capital.

A Polícia atirava as bombas. [...] vi pessoas sangrando de ferimentos de bala de borracha, e não nas pernas, pessoas atingidas na barriga, no braço, até na cabeça, e eu percebi aquilo com muita revolta porque como eu estudei um pouco da técnica policial eu sei que as chamadas munições de motim, elas são muito fortes, logo elas devem ser atiradas para o chão, para que elas se espalhem e elas atinjam a parte das pernas, onde é menos nocivo. E os policiais militares, eles miravam na direção do tronco para cima, o que, inclusive, segundo a recomendação da ONU, é ilegal, é considerado crime de guerra. (Milton Hatoum - Professor e escritor brasileiro)

Os professores sentiram na pele o que Mészáros (2002) teoriza: toda a sociedade é afetada pela crise: "afeta a totalidade de um complexo social em todas as suas relações com suas partes constituintes ou subcomplexos, como também a outros complexos aos quais é articulada, [...] o capital não pode ter outro objetivo que não sua própria autorreprodução" (pp. 797-800) e o faz subjugando tudo e todos. Embora percebamos a crescente barbárie, não podemos pensar que o sistema esteja prestes a colapsar, e sim que ele se auto corrói para se manter. $O$ que foi relatado pelos professores, é preciso ser relacionado com a violência com o todo. Para Bezerra e Medeiros (2015, p. 4):

a realidade demonstra que a partir da crise estrutural do capital as contradições imanentes à lógica do capital tornaram-se mais agudas ao adotar este projeto social/liberal que vem conduzindo o aumento da taxa de exploração dos trabalhadores, com a desregulamentação cada vez mais crescente dos direitos trabalhistas, e a restrição de intervenção do Estado no setor das políticas públicas, estabelecendo novas relações de produção por meio de trabalhos precários. [...] O sistema do capital não é capaz de extirpar as causas das crises, mas tenta remediar as suas consequências, pois não vai pôr em xeque a sua reprodução incontrolável.

É necessário ter clareza em relação a essa crise, após décadas de neoliberalismo, com o predomínio do "princípio da austeridade sobre os gastos sociais e da liberalização dos fundos públicos para socorrer os negócios do capital, os resultados são funestos e atemorizadores" (Paniago, 2014, p. 1).

Em continuidade, os professores apontaram para 
a impotência e o desalento, "a falta de refúgio para socorrer os feridos e o retorno".

Havia um muro de policiais rodeando a Assembleia e na rampa tinha policiais do BOPE armados; no teto tinha atiradores de elite, com metralhadoras apontadas para gente, dois helicópteros. [...]. Aí, nesse momento, estourou uma bomba embaixo do caminhão, muita fumaça. Nós ficamos lá até às sete horas da noite, e as bombas caindo. Mas a gente não saiu dali porque mesmo depois de toda aquela violência a gente acreditava que ia ganhar..., na calada da noite, enquanto deu aquela trégua para baixar a fumaça e socorrer os feridos, os deputados foram lá e votaram. Nossa! Aquilo foi assim triste, sabe, um silêncio de repente. A rua estava cheia. Estava chovendo uma chuva fria e o prefeito abriu a prefeitura para a gente se abrigar porque a gente não tinha onde se abrigar e socorrer os feridos. Fez um cordão para socorrer os feridos ali na prefeitura. Voltar para os ônibus, encontrar alguém... [choro] E na volta do ônibus, aquele cheiro de vinagre, aquilo não vai sair nunca do meu nariz. Cheiro de fumaça de coisa queimada... sabe, parecia que tinha queimado a sua roupa... sabe, horrivel. Ninguém falava... sabe, todo mundo sentou ali e ficou, assim, como se não acreditasse naquilo que tinha acontecido. Um pesadelo, uma coisa desoladora, de filme. Você não tinha o que falar para o colega do lado. (Frida Kahlo - Pintora mexicana).

Cenas como as relatadas pelos professores, nas quais a Polícia agiu com extrema violência para reprimir os manifestantes, sem socorro aos trabalhadores feridos, evidenciam a legitimação dos interesses da classe dominante, e propagam a naturalização das desigualdades sociais. As interações sociais encontram-se esvaziadas e a organização social contribui para o individualismo e competitividade. Neste sentido, Hobsbawn (1995, p. 24) escreve sobre uma das transformações do mundo no final do século XX seria a "desintegração de velhos padrões de relacionamento social humano", suscitando assim:

o predomínio do individualismo [...] essa sociedade formada por um conjunto de indivíduos egocentrados sem outra conexão entre si, em busca apenas da própria satisfação [...] o lucro, o prazer, ou seja, lá o que for [...] sempre implícita na teoria capitalista (Hobsbawn, 1995, p. 25).

Alguns trabalhadores (policiais, assessores de políticos etc.), no dia 29 de abril de 2015 não se comportam como pertencentes à classe trabalhadora: "perdem o sentimento de coletividade, tal comportamento de- monstra ser fruto da ideologia do capital que faz com que se desenvolvam nos trabalhadores atitudes competitivas, individualistas, que se tornem indiferentes às causas coletivas" (Galvão, 2015, p. 7).

Indagados sobre como era lembrar e relatar sobre o ocorrido no dia 29 de abril, os professores expressaram não ser uma tarefa fácil, pois sentimentos como os de frustração, tristeza e dor reavivam. Alguns alegaram que tentaram não falar para esquecer, num posicionamento deliberado de negação, mas que consideram importante relatar.

Olha, o relato eu acho que é fundamental para não esquecermos. E sempre que a gente fala, mesmo na sala de aula, quando voltamos para repor as aulas, dizer na sala de aula do ocorrido no dia 29 é uma coisa que traz esse frio na barriga, essa sensação de impotência que a gente sofreu no dia, e essa talvez seja uma das piores situações (Ernesto Guevara - Médico argentino, revolucionário marxista).

Três professores demonstraram sentimento de impotência, derrota e decepção. Onze professores demonstraram em suas falas que, apesar de todo o sofrimento e a tristeza, acreditam que esse relato pode contribuir para a elaboração das dores adquiridas no dia 29. Identificamos nos discursos certa dificuldade para fazer uma análise mais abrangente, como nos relatos da falta de preparo deles para o momento do confronto. Os professores não esperavam tamanha violência, acreditando em uma manifestação pacífica relacionada à "cultura da tolerância e da paz", discurso muito propagado pelo governo neoliberal, e presente em vários projetos financiados pelo Estado do Paraná. Ele oculta as contradições presentes na sociedade de classes e tende a levar os trabalhadores a acreditarem que a violência ocorre somente quando são atacados em seus corpos físicos.

Com base em Vásquez (1977), a violência, em seus diferentes modos de se manifestar, não será dirigida apenas aos aspectos físicos (como vemos nos relatos dos professores), mas ao ser social e à sua consciência. As diferentes formas de violência que se manifestam no cotidiano são "expressão de uma violência mais profunda: a exploração do homem pelo homem" (Vásquez, 1977, p. 395).

Para Vásquez (1990), quando o Estado se sente ameaçado de perder o poder, vale-se de ações coercitivas na defesa dos interesses da classe dominante, para defender a elite burguesa. Há a "aplicação de diferentes formas de coerção que chegam inclusive às ações armadas com o objetivo de conquistar ou manter domínio econômico e político, ou de conseguir esses ou aqueles privilégios" (Vásquez, 1990, p. 381).

Pedimos que falassem sobre quais senti- 
mentos emergiram ao retornarem para a escola onde atuam, após 29 de abril de 2015. Todos relataram seus sentimentos de dor, derrota, sofrimento, impotência, frustração, humilhação, desvalorização, desesperança: "É um sentimento, assim, na verdade, de dor. Eu nunca vi, uma coisa absurda aquilo. Foi desproporcional. É desumano". (Paulo Freire)

Indagados sobre a interferência na vida emocional, relataram sentimentos relacionados à desistência, falta de vontade de ir para a escola, sensação de perda, episódios de choro, desespero, pânico. Alguns entrevistados alegaram que, após o episódio, passaram a desenvolver certa aversão à Polícia Militar (PM), sentindo medo quando avistam viatura com policial militar, quando encontram com PM na escola, ou mesmo quando escutam barulhos de sirenes, de helicóptero.

Ante essa situação rememorada, e voltando ao eixo "Formação e atuação profissional", ao serem questionados sobre se, nas escolas onde atuam, haviam participado de cursos, oficinas ou grupos de estudos que abordassem a temática violência e a violência na escola, nos últimos quatro anos de trabalho: $64,29 \%$ dos professores responderam negativamente, e 35,71\%, afirmativamente.

No eixo "Percepções da Educação/escola atual", ao responderem sobre como têm sido ser e atuar como professor da escola pública nos últimos anos, sete (50\%) responderam que, apesar das dificuldades, se identificam e gostam da profissão, que é "apaixonante" e se sentem satisfeitos por contribuir para a vida dos alunos de forma positiva. Sete (50\%) responderam que tem sido difícil, percebem "cada ano mais difícil" e apontam sentimento de frustração, decepção, desgaste, incerteza, desejo de trocar de profissão, adoecimento devido à falta de respeito com a figura do professor e indisciplina.

Com relação ao eixo "Violência no mundo e na educação", os participantes foram indagados sobre como percebem a violência fora do muro da escola e qual o impacto no cotidiano das pessoas, de acordo com suas leituras e concepções teóricas. Todos responderam que percebem a violência como parte da atual organização social, inerente à sociedade capitalista e que tem levado ao aumento das desigualdades sociais e das diferentes formas de corrupção.

Com relação ao tipo de violência vivenciada na escola onde atuam, onze entrevistados (78,57\%) relataram que vivenciaram violência física e verbal; e três professores entrevistados $(21,43 \%)$ responderam ter vivenciado violência física.

Ao serem questionados se percebem ter havido um aumento das situações de violência no ambiente escolar onde atuam, $100 \%$ responderam afirmativamente, classificando o aumento como significativo.

No eixo "Violência no mundo e na Escola", quando questionados sobre as causas da violência na escola, oito professores $(57,14 \%)$, responderam que as causas estão relacionadas a questões sociais, tais como o modo como a sociedade está organizada, a desigualdade social, a corrupção que leva à miséria e à opressão psicológica, interferindo, assim, nas famílias, que não conseguem educar os seus filhos ("dar limites"). Quatro $(28,57 \%)$ responderam como possível causa a falta de preparo dos profissionais da escola em mediação de conflitos, o que levaria às dificuldades de relacionamento entre professor (educador) e aluno e vice-versa. Dois professores $(14,29 \%)$ responderam que as mídias são as causas da violência na escola, atribuem às redes sociais a naturalização de diferentes formas de violência.

Quando os entrevistados foram abordados sobre o que deveria ser feito para o enfrentamento da violência na escola, seis $(42,86 \%)$ pontuaram que a escola deveria trabalhar com a prevenção da violência, sugerindo que se oportunizassem atividades culturais, como aulas de arte, dança, música, atividades esportivas, abertura da escola para a participação da comunidade; quatro responderam que o professor deveria receber melhor formação para lidar com conflitos e trabalhar com temas como respeito, diversidade e relacionamento interpessoal; dois $(14,29 \%)$ sugeriram formar equipes multiprofissionais na escola, com psicólogos e assistentes sociais; e dois professores $(14,29 \%)$ acreditam que a escola não consegue resolver o problema, pois este é muito amplo e envolve mudança que deveria ocorrer na sociedade como um todo, isto é, no modo de produção do atual sistema.

No eixo "Perspectivas para a Educação e Vida Pessoal", os professores responderam sobre as expectativas que eles têm em relação à educação, como docentes, e por quanto tempo se imaginam atuando nessa profissão. Onze professores $(78,57 \%)$ relataram que gostariam de continuar na profissão, pois acreditam que ela tende a melhorar e que a educação pode contribuir na formação do ser humano. Relevante salientar que, dos onze professores que querem continuar na profissão, dois (14,29\%) alegaram que mesmo sabendo das expectativas negativas, querem continuar sendo professores.

\section{CONSIDERAÇÕES FINAIS}

Esses entrevistados estiveram em Curitiba na luta pela educação pública, durante o governo de Carlos Alberto Richa, quando houve o "massacre" e não "confronto" entre a polícia e os professores, tamanha a disparidade de recursos entre as partes. Uma com corpos e vozes, e outra com arsenal e táticas de extrema violência (Carvalho, 2016), engajados com uma concepção de educação e sociedade aqui analisada e criticada.

Diante de todas as dificuldades expostas e da complexidade da profissão, os entrevistados verbalizam 
muita indignação pelos fatores conjunturais e políticos. Consideraram muito importante narrar o que haviam passado, as situações de grande violência, considerando o uso intencional de força física contra eles, resultando em ferimentos, danos psicológicos, prejuízo ao desenvolvimento, conforme a OMS (2014).

Tais experiências, contudo, não afastam todos os professores da valorização da profissão, talvez por ainda manterem certa crença em melhorias na área da educação. Oliveira (2011) ao comentar sobre a pesquisa lançada pela UNESCO, denominada "Professores do Brasil: impasses e desafios", que apresenta dados das condições de trabalho docente, carreira e remuneração, revela que o idealismo e a certeza de que contribuirão na formação de novas gerações são componentes fortes para que muitos professores não abandonem a docência. Mesmo sob forte carga emocional que a temática lhes suscita, foi significativamente maior o número de professores entrevistados que declararam querer continuar (11) na profissão de docente, comparado ao número dos que não têm essa pretensão (03). Esse dado é relevante quando pensamos que o professor desenvolve trabalho não material, e que deve ser agente mediador que contribui para significar o mundo junto aos alunos por meio dos conteúdos que ensina, e que isso está diretamente relacionado à constituição do psiquismo e da consciência - os seres humanos são formados pela/ na sociedade na qual vivem (Vygotski, 1996).

As influências externas e objetivas, por serem o ponto de partida e determinantes na ação recíproca entre o ser humano e a realidade concreta, condicionam toda atividade psíquica dos homens, todos os traços de sua personalidade. Não restam dúvidas da impossibilidade de constituição da personalidade à parte das relações sociais sob reprodução do capital e, da mesma forma, de conceber condutas violentas como se fossem herança genética, pois, como vimos defendendo, "as propriedades do psiquismo humano são determinadas pelas relações reais do homem com o mundo, relações que dependem das condições históricas objetivas de vida. São essas relações que criam as particularidades estruturais da consciência humana" (Leontiev, 1978, p. 138). Por essa direção, fica a responsabilidade de continuarmos desvelando a gênese e o desenvolvimento do psiquismo humano, inclusive das condutas individuais, mas considerando a existência concreta dos sujeitos.

Assim, ao analisarmos historicamente a violência, percebemos que esta se vincula a uma dada forma de produção de vida. Para Silva (2006) e Barroco e Costa (2014) o fenômeno é social e historicamente construído; não se origina, pois, nas manifestações individuais dos sujeitos. Ainda, os dados encontrados nos permitiram verificar como os professores percebem a violência na escola e quais seriam suas perspectivas em relação à educação e à vida. Tais dados demonstram que o desconhecimento sobre alguma política pública de enfrentamento a violência atinge $92,86 \%$ dos professores entrevistados.

Da mesma forma, a participação destes profissionais em cursos, oficinas ou grupos de estudos que abordam a temática violência e violência na escola nos últimos quatro anos de trabalho é baixa, correspondendo a $35,71 \%$ especificamente. Fica evidente que não se trata apenas de desatenção dos professores tal desconhecimento, mas de ausência ou insuficiência de políticas públicas, sobretudo de formação continuada, em serviço. Também se evidencia a falta de preparo teórico-técnico na formação inicial (graduação) para lidarem com a violência.

Concluímos como necessária a continuidade de pesquisas que expliquem a violência e o contexto que a produz, principalmente, a violência relacionada à educação, objeto complexo e com contínuos desdobramentos. Em 2015, a violência física apontada contra os professores da educação pública do Paraná impactou a categoria e a sociedade. Em 2020, essa violência no Brasil se apresenta sob outras roupagens, sobretudo no plano moral, das ideias, como pode ser identificado pelas atuações do governo federal, pelo divulgado por diferentes associações (ANPEd, ANPEPP, SBPC, ABRAPEE etc.), e faz-se imperativo que ela seja alvo do interesse de todos (professores e pesquisadores), visto que os impacta direta ou indiretamente e diz respeito à formação desta e das novas gerações.

Ante a constatação de que a violência não findou e que ela pode se agudizar, é crucial lembrarmos o que Saviani (2003) postula: a função primordial da escola é garantir o acesso ao conhecimento científico, socializando a riqueza cultural construída historicamente pela humanidade. Por isso, há a necessidade de se estudar, discutir e buscar formas de efetivar tal acesso para todos e, neste caso específico, para toda a comunidade escolar que sofre diante de situações de violência que têm prejudicado o processo ensino-aprendizagem. Essa inacessibilidade já é, em si, ato violento!

\section{REFERÊNCIAS}

Abramovay, M.; Rua, M. G. (2002). Violências nas escolas. Brasília: UNESCO, Instituto Ayrton Senna, Unaids, Banco Mundial, Usaid, Fundação Ford, Consed, Undime.

Barreira, C. (1999). Ligado na galera. Brasília: UNESCO, FNUAP, UNICEF, Instituto Ayrton Senna.

Barroco, S. M. S.; Costa, M. L. S. (2014). Considerações do marxismo e da Psicologia Histórico-Cultural para a compreensão da violência. Anais do VIII Encontro Regional Rio de Janeiro da ABRAPSO: O psicólogo social na cidade: ações territoriais, lutas políticas e subjetividade (pp. 38 
- 39). Rio de Janeiro, RJ. Recuperado de http://newpsi. bvs-psi.org.br/eventos/VIII_encontro_regional_rio_ abrapso2014.pdf Acesso em 24 mar. 2021

Bezerra, A. L. S.; Medeiros, M. G. (2015). A crise estrutural do Capital: reiterações e inflexões para a classe trabalhadora e o Serviço Social. Anais do VII Jornada Internacional de Políticas Públicas, Universidade Federal do Maranhão UFMA. http://www.joinpp.ufma.br/jornadas/joinpp2015/ eixo2.html.

Carvalho, A. M. (2017). A violência na educação: o que expressam professores das escolas públicas da rede estadual no município de Cascavel/PR que passaram por situações de violência (Dissertação de Mestrado). Programa de Pós-graduação em Psicologia, Universidade Estadual de Maringá.

Castro, M. G.; Abramovay, M.; Rua, M. G.; Andrade, E. R. (2001). Cultivando vida, desarmando violências: experiências em educação, cultura, lazer, esporte e cidadania com jovens em situação de pobreza (3ae ed.). Brasília: UNESCO, Brasil Telecom, Fundação Kellogg, Banco Interamericano de Desenvolvimento.

Chauí, M. (1999). Introdução à Filosofia. Porto Alegre: Bertand Brasil.

Costa, M. L. S. (2014). Violência nas escolas: contribuições da psicologia histórico-cultural para seu enfrentamento nas escolas (Dissertação de Mestrado). Programa de Pós-graduação em Psicologia, Universidade Estadual de Maringá.

Fonseca, F. (2011). Mídia, poder e democracia: teoria e práxis dos meios de comunicação. Rev. Bras. Ciênc. Polít., 6, 41-69.

Galvão, F. S. (2015). O precariado no Brasil contemporâneo: processo de (des)organização política em tempos de crise. Anais do VII Jornada Internacional de Políticas Públicas. Universidade Federal do Maranhão-UFMA. Recuperado de: http://www.joinpp.ufma.br/jornadas/joinpp2015/eixo2. html. Acesso em 12 mar. 2021

Gil, A. C. (1996). Como elaborar projetos de pesquisa. São Paulo: Atlas.

Hobsbawn, E. (1995). A era dos extremos: o breve século XX (1914-1991). São Paulo: Companhia das Letras.

Leontiev, A. N. (1978). O desenvolvimento do psiquismo (Duarte, M. D., Trad.) Lisboa: Livros Horizonte.

Leontiev, A. N. (1988). Os princípios psicológicos da brincadeira pré-escolar. In: Vigotski, L. S. A.; Luria, A. R.; Leontiev, A. N. (Ed.), Linguagem, desenvolvimento e aprendizagem (10a ed.) (Villalobos, M. da P., Trad.). São Paulo: Ícone/EDUSP.

Luria, A. R. (1979). A atividade consciente do homem e suas raízes histórico-sociais. In: Luria, A. R. Introdução Evolucionista à Psicologia (Curso de Psicologia Geral, vol. I) (pp. 71-84). Rio de Janeiro: Civilização Brasileira.

Martin-Baró, L. (1997). Accion e ideologia - Psicología social desde Centroamérica (8 $8^{\mathrm{a}}$ ed.). El Salvador: UCA Editores.

Martin-Baró, L. (2015). La institucionalización de la calumnia.
Teoría y Crítica de la Psicología 6, 532-542. (Original publicado em 1981). Recuperado de: http://www.teocripsi. com/ojs/ Acesso em 20 jun. 2020.

Martins, L. M. (2006). As aparências enganam: divergências entre o Materialismo Histórico Dialético e as abordagens qualitativas de pesquisa. $29 \underline{a}$ reunião da ANPED, Caxambu, MG.

Mészáros, I. (2002). Para além do capital: rumo a uma teoria da transição. (Castanheira, P. C.; Lessa, S. Trad.). São Paulo: Editora da UNICAMP/Boitempo.

Minayo, M. C. (1999). Fala galera - juventude, violência e cidadania na cidade do Rio de Janeiro. Rio de Janeiro: Garamond.

Oliveira, R. C. (2011). Entrevista: Ricardo Costa de Oliveira: Entrevista concedida a Rogério Waldrigues Galindo. Gazeta do povo. Recuperado de: <http://www.gazetadopovo.com. br/vida-publica/a-politica-vem-se-tornando-negocio-defamilia-no-parana-daedg5khe2xep7latvv9o0kem>. Acesso em 15 jan. 2015.

Organização Mundial de Saúde. ([2014). Relatório Mundial sobre a prevenção da violência 2014 (Traduzido do original Global Status Report on Violence Prevention). Núcleo de Estudos da Violência da Universidade de São Paulo 2015. Recuperado de: https://apps.who.int/iris/ handle/10665/145086. Acesso em 15 jun 2020.

Paniago, M. C. S. (2014). A crise estrutural e a centralidade das classes sociais. Revista Katálysis, 17(1), 41-49.

Instituto Brasileiro de Geografia e Estatística - IBGE. (2009). Pesquisa nacional de saúde do escolar 2009. Rio de Janeiro: IBGE. Recuperado de: https://biblioteca.ibge.gov.br/ visualizacao/livros/liv43063.pdf. Acesso em 15 jun 2020.

Instituto Brasileiro de Geografia e Estatística - IBGE. (2013). Pesquisa nacional de saúde do escolar 2012. Rio de Janeiro: IBGE. Recuperado de https://biblioteca.ibge.gov.br/ visualizacao/livros/liv64436.pdf Acesso em 15 jun. 2020.

Instituto Brasileiro de Geografia e Estatística - IBGE. (2016). Pesquisa nacional de saúde do escolar 2015. Rio de Janeiro: IBGE. Recuperado de: https://biblioteca.ibge.gov.br/ visualizacao/livros/liv97870.pdf Acesso em 15 jun. 2020.

Ros, A. C. P. (2014). Violência familiar, pauperismo e sociabilidade burguesa: a vida das famílias atendidas no CREAS II em Ribeirão Preto (Dissertação de Mestrado). Faculdade de Ciências Humanas e Sociais, Universidade Estadual Paulista, Franca, SP.

Saviani, D. (2003). Pedagogia histórico-crítica: primeiras aproximações (8a ed.). Campinas: Autores Associados.

Silva, N. R. (2006). Relações sociais para a superação da violência escolar e processo formativo de professores (Tese de Doutorado). Programa de Estudos de Pós-graduação em Educação, Pontifícia Universidade Católica - PUC, São Paulo.

Vázquez, A. S. (1977). Filosofia da Práxis. Rio de Janeiro: Paz e Terra. 
Vygotski, L. S. (1996). Obras escogidas. Tomo IV. Madri: Visor. (Original publicado em 1984).
Vygotski, L. S. (2000). Obras escogidas. Tomo III (2a ed.). Madri: Visor. (Original publicado em 1983).

Recebido: 05 de maio de 2019

Aprovado: 26 de junho de 2020 